\title{
CRISIS ECONÓMICA, CONFIANZA INSTITUCIONAL Y LIDERAZGOS POLÍTICOS EN ESPAÑA
}

\author{
ECONOMIC CRISIS, INSTITUTIONAL CONFIDENCE AND POLITICAL \\ LEADERSHIP IN SPAIN
}

\author{
José Francisco Jiménez Díaz \\ Universidad Pablo de Olavide, Sevilla. España/Spain \\ josefco@upo.es
}

Recibido/Received: 12/01/2013

Aceptado/Accepted: 16/03/2013

\section{RESUMEN}

Este artículo se propone analizar, de modo exploratorio, los efectos de la crisis económica en los principales liderazgos políticos de España. Para entender la política española de los últimos años es necesario conocer las consecuencias de dicha crisis sobre los líderes e instituciones políticas que éstos dirigen. En las democracias representativas los líderes políticos han de mantener vínculos de confianza con sus seguidores para justificar las acciones políticas de los primeros. Por ello, y según las interpretaciones teóricas y datos expuestos en este trabajo, la confianza institucional se torna en un factor clave para poder comprender los efectos de la crisis económica sobre los liderazgos políticos. Así, el deterioro de la confianza en las instituciones está asociado con la creciente deslegitimación de los principales líderes políticos y con una crisis profunda de legitimidad política.

\section{PALABRAS CLAVE}

Liderazgo democrático, crisis económica, instituciones, confianza.

\section{SUMARIO}

1. Introducción: la encrucijada de diversas crisis. 2. Sobre la crisis económica española y sus efectos en los liderazgos políticos. 3. Confianza política y liderazgos democráticos: ¿una relación necesaria? 4. Desconfianza en los liderazgos e instituciones políticas. 5. A modo de reflexiones. Bibliografía.

\begin{abstract}
This paper analyzes the effects of the economic crisis in main political Spanish leaders in an exploratory way. For understanding the politics of the recent years is necessary to know the consequences of this crisis on leaders and political institutions that they manage. In representative democracies, political leaders have to maintain confidence with their followers to justify the political actions of the formers. Therefore, and according to theoretical interpretations and data presented in this paper, institutional confidence becomes a key factor to understand the effects of the economic crisis on the political leadership. Thus, the decline of institutional confidence is related with the increasing delegitimization of main political leaders and with the profound crisis of political legitimacy.
\end{abstract}

\section{KEYWORDS}

Democratic leadership, economic crisis, institutions, confidence. 


\section{CONTENTS}

1. Introduction: the crossroads of several crises. 2. The Spanish economic crisis and its effects on the political leadership. 3. Political confidence and democratic leadership: a necessary relationship? 4. Distrust in the leaderships and political institutions. 5. Reflections. References.

\section{INTRODUCCIÓN: LA ENCRUCIJADA DE DIVERSAS CRISIS}

Atendiendo a varios estudios de opinión pública en España, elaborados por el Centro de Investigaciones Sociológicas (CIS) en los últimos años, uno de cada cuatro ciudadanos piensa que la clase política es el principal problema político del país y para uno de cada dos españoles quienes gobiernan desempeñan mal o muy mal su acción política (CIS, 2012: estudio 2.951; CIS, 2011, estudio 2.909). Ello supone, entre otras cosas, un claro cuestionamiento de la calidad de los representantes políticos, a la vez que comporta una creciente desconfianza hacia la política que dichos representantes desarrollan y una gran preocupación por la forma en que se ejerce el gobierno en España. Ello parece que no es independiente de la evolución económica, pues la ciudadanía se siente poco representada por los poderes políticos elegidos democráticamente (poder legislativo y ejecutivo), al tiempo que se extiende la percepción "de la incapacidad de los gobernantes para dar solución a sus problemas cotidianos, atajar la corrupción o imponer sus decisiones a los poderes económicos o instituciones que escapan al control democrático" (Estefanía, et al., 2012:22).

Asimismo, según las varias auditorías elaboradas sobre la calidad de la democracia en España se muestran dos datos recurrentes y que cada año, desde 2007, manifiestan más claramente los expertos entrevistados. Por una parte, empeora la percepción de que el Gobierno disponga de autonomía real en el desarrollo de sus políticas frente a los grandes intereses económicos y, a la vez, se deteriora de forma acusada la confianza en la acción del Gobierno para resolver los principales problemas de los ciudadanos. Por otra parte, la extensión de la corrupción política se torna en un problema cada vez más central de la democracia, pues se expande por gobiernos locales y autonómicos de distinta orientación ideológica (Estefanía, et al, 2010). Ambos hechos llevan a una clara erosión de la confianza de los ciudadanos en las principales instituciones del Estado español, lo que produce una crisis de confianza generalizada e incertidumbre ciudadana que pueden acarrear importantes efectos sobre el sistema democrático español y los actores en él implicados.

A dicha crisis de confianza institucional se le une, en España, la profunda crisis económica-financiera que vive el país desde, por lo menos, el año 2008. Entre los años 2008 y 2012 se ha podido comprobar que la crisis económica española adopta un perfil realmente dramático en lo que respecta a la creciente e incontrolable tasa de paro, en realidad la mayor tasa de los países que conforman la OCDE (Organización para la Cooperación y el Desarrollo Económico) y, por ende, mayor tasa de paro que la de los países ya rescatados en la Unión Europea (Portugal, Irlanda y Grecia).

En consecuencia, la crisis económica en España ha producido cambios evidentes sobre las prácticas y valores que han de asumir tanto los líderes políticos como los ciudadanos en la gestión y vivencia de esta situación. Así, mientras que durante el inicio de la crisis económica (2008 y 2009), muchos líderes de la Unión Europea (UE) y también los 
españoles apostaron por planes de estímulo del gasto público e incluso por una refundación del sistema capitalista; desde principios del año 2010 se impusieron medidas económicas de austeridad, de ahorro y/o contención del gasto público en todos los Estados de la UE, especialmente en los países del sur pertenecientes al euro. Además, estos países, entre los que se encuentran España, están viviendo una fase de verdadera mutación políticainstitucional y socioeconómica debido a los problemas relativos al creciente endeudamiento privado y público. Es preciso recordar que en el caso español el verdadero problema de endeudamiento proviene del sector privado y no tanto del sector público, pues este último sector se ha tenido que endeudar, sobre todo, para afrontar los graves problemas derivados de la propia crisis financiera. En 2007, las cuentas del sector público español estaban en superávit, si bien el peligro de que estallara la burbuja inmobiliaria era muy probable, como luego se comprobó.

En cualquier caso, se imponen por doquier valores y prácticas percibidas en un segundo plano en las sociedades de consumo occidentales, como son la austeridad, el valor del trabajo, la estabilidad económica y el ahorro. Efectivamente, los más de cinco millones y medio de parados españoles han estado obligados a vivir en la austeridad y precariedad desde hace bastante tiempo, y entre sus relaciones de preferencias parecen sobresalir la frustrada, para ellos, estabilidad y seguridad en el trabajo. Las consecuencias sociales de todo ello es un creciente empobrecimiento de las clases medias y bajas en España, que están viendo reducidos y/o extinguidos sus salarios o subsidios de desempleo. Ello puede conllevar un cambio de modelo de sociedad, puesto que, por un lado, "el salario del trabajador ya no hace posible mantener el consumo" y, por otro, "los desempleados de hoy no tienen posibilidad de volver a tener una vida normal de trabajo" (Sassen, 2012:26). Algunos estudiosos argumentan que posiblemente se necesitarán al menos diez años para volver a recuperar el nivel de empleo que el país tenía en 2007.

Asimismo, la profundidad y prolongación de la crisis, así como sus consecuencias relativas al aumento de la pobreza, la creciente desigualdad social y el deterioro del Estado social, cuestionan para parte de la población algunos de los principios y valores básicos en los que se sustenta la convivencia democrática, como son la justicia y la equidad. Por ello, aparece entre la ciudadanía española una clara "percepción del injusto reparto de los frutos del crecimiento y de los costes de la crisis, y una sensación de creciente exclusión de diversos grupos de la población, en especial de los más jóvenes" (Estefanía et al., 2012: 17). Sin duda la pervivencia de la desigualdad social incide en la menguante confianza de los ciudadanos en las instituciones y líderes políticos. Sin embargo, en periodos de estabilidad económica y en diversos países con democracias consolidadas se viene observando desde, al menos, principios de la década de los ochenta una tendencia hacia el aumento de la desconfianza en la política, precisamente el elemento fundamental con el que se construye la vida democrática (Villoria, 2005; Dogan, 2005; Norris, 1999; Inglehart et al., 2004; Pharr y Putnam, 2000). Por ello, realmente, la crisis económica está actuando como elemento amplificador de una mayor desconfianza hacia los líderes políticos e instituciones democráticas.

De esta forma, las consecuencias políticas-electorales de la crisis económica son cada vez más evidentes y variadas. Así, muchos han sido los líderes políticos en toda la Unión Europea, sobre todo presidentes del gobierno y líderes de la oposición, que o bien se han visto removidos de sus cargos por no obtener el apoyo de los ciudadanos en las urnas, o bien han experimentado una progresiva disminución de todo tipo de apoyos recibidos por la ciudadanía (votos, confianza y/o credibilidad). En efecto, durante la crisis se muestra 
una reducción progresiva de los niveles de confianza que los ciudadanos españoles depositan en los líderes políticos y en las instituciones democráticas más importantes, como el parlamento, los partidos políticos, el gobierno central y el poder judicial, hasta el punto de cuestionar estas instituciones centrales de la democracia.

Partiendo de este complejo contexto, el propósito del presente trabajo es analizar los efectos de la crisis económica, producida entre 2008 y 2012, en los principales líderes políticos españoles, así como en las más relevantes instituciones democráticas. Para ello, en primer lugar, se elabora un breve relato de los efectos de la crisis en los líderes políticos españoles y europeos. Luego, se muestra la estrecha relación entre los conceptos de confianza institucional y liderazgo democrático. Más tarde, se confirma un progresivo cuestionamiento cívico de los principales líderes políticos españoles e instituciones democráticas. $\mathrm{Y}$ por último, se plantean un conjunto de reflexiones enfocadas a comprender el presente deterioro de la confianza institucional (o política) en el contexto español y europeo.

\section{SOBRE LA CRISIS ECONÓMICA ESPAÑOLA Y SUS EFECTOS EN LOS LIDERAZGOS POLÍTICOS}

Durante el año 2010, cuando los efectos de la crisis financiera-económica ya eran evidentes en España y en otros países de la Unión Europea, el ex-presidente del Gobierno Felipe González reclamaba un renovado liderazgo para afrontar la crisis en los siguientes términos: "Hace falta un liderazgo claro y una capacidad de diálogo sostenida. La situación de la Unión Europea es de emergencia, tanto por la dureza de la crisis y sus efectos en nuestra realidad social y económica, como por los cambios estructurales que debemos producir para afrontarla y encauzar nuestro futuro a medio y largo plazo" (González, 2010: 11-12). Desde otro punto de vista, los autores del Informe sobre la democracia en España 2010, mostraban que el sistema democrático español estaba "golpeado de modo muy directo por las dudas ciudadanas en torno a la calidad de las respuestas políticas a la crisis en términos de eficacia y de reparto de las cargas" (Estefanía, et al., 2010:14).

Cuando los liderazgos políticos viven bajo la presión y los efectos de una crisis tan compleja, grave y profunda como la presente, han de afrontar las siguientes tareas para ofrecer un relato creíble sobre la crisis, a saber: "dar sentido, adopción de decisiones, proporcionar significado, terminación y aprendizaje [derivado de la crisis]" (Boin et al, 2007:29). La hipótesis de este trabajo es que a lo largo de la crisis económica vivida en España, desde 2008, los principales líderes políticos nacionales y europeos aún no han sabido proporcionar los sentidos y significados adecuados para intentar ofrecer un diagnóstico creíble de la crisis y, en consecuencia, poder ofrecer respuestas eficaces a la misma. Así, las decisiones políticas adoptadas se ven desbordadas por el curso de los acontecimientos, lo que produce entre los ciudadanos un progresivo malestar democrático, así como un notable grado de desconfianza hacia los líderes e instituciones políticas.

Efectivamente, la vida política europea del último lustro, y en particular la española, no se comprende bien sin conocer los efectos que sobre ella ha tenido la evolución económica internacional y nacional. Los efectos de las crisis financiera y económica sobre los liderazgos políticos han sido muy diversos dependiendo de la situación de cada país y de cada líder, pero, sin duda, las nefastas consecuencias de dichas crisis han desgastado la credibilidad y la confianza depositada por los ciudadanos en muy distintos gobiernos de 
toda Europa. Así sucedió con el último gobierno liderado por José Luis Rodríguez Zapatero, entre los años 2008 y 2011. El líder del PSOE se percató muy tarde de la verdadera gravedad de la situación. Tardó casi un año en reconocer la gravedad de la crisis y aún más tiempo en empezar a tomar medidas de choque. Si bien, las primeras medidas desarrolladas por el gobierno de Zapatero se correspondían, más o menos, con su discurso político y algunas de las promesas electorales de 2008 (Plan Español para el Estímulo de la Economía y el Empleo y respeto de los derechos sociales), la política económica que impulsó el gobierno socialista a partir del mes de mayo de 2010 empezó a contradecir radicalmente el discurso socialdemócrata y a promover medidas ortodoxas propuestas desde instancias económicas internacionales, pese a ser consciente del alto coste personal y electoral que tendría su cambio de posición. En el Debate sobre el Estado de la Nación de 2010, celebrado a mediados de julio, el Presidente del Gobierno mostró su radical cambio discursivo: "Tomaré las decisiones que España necesita aunque sean difíciles. Voy a seguir ese camino cueste lo que cueste y me cueste lo que me cueste" (Rodríguez Zapatero citado en Garea, 2010).

Por tanto, debido al gran giro en su discurso político y la impopularidad de las medidas económicas que ello comportaba, la credibilidad de Rodríguez Zapatero y, en consecuencia, su liderazgo político experimentó un notable proceso de decadencia y de cuestionamiento interno en su partido que lo llevó al límite en el ejercicio de las tareas de gobierno (Jiménez y Collado, 2011:147-151). Todo ello supuso una fuerte caída en la intención de voto al PSOE, así como el desplome en la valoración de los líderes políticos socialistas mostrado por diversos sondeos de opinión publicados entre 2010 y 2011.

A lo largo del verano de 2011, sobre todo en el mes de agosto, la situación económica y política española fue realmente turbulenta, sobre todo debido a la negativa evolución de los indicadores económicos y financieros, así como por el desarrollo de un notable malestar ciudadano reflejado, en parte, en el movimiento 15-M desde mayo de 2011. De hecho, la adversa situación económica llevó a que Rodríguez Zapatero y Mariano Rajoy pactaran la modificación del artículo 135 de la Constitución Española de 1978, a finales de agosto de 2011, sin recabar el consenso de las demás fuerzas políticas nacionales, pero que satisfacía las demandas de ajuste presupuestario requeridas por la Unión Europa.

En estas circunstancias, los candidatos del PP y PSOE a la presidencia del gobierno (Mariano Rajoy y Alfredo Pérez Rubalcaba, respectivamente) concurrieron a una campaña electoral, la de las Elecciones Generales del 20 de noviembre de 2011, caracterizada por la baja movilización y el escaso o nulo debate real de las propuestas políticas, lo que posiblemente benefició al PP ya que este partido había optado por una estrategia electoral centrada en la gestión económica del gobierno socialista. El Partido Popular, aún obteniendo una mayoría absoluta histórica superior a la que consiguió Aznar en el 2000, apenas había incrementado el número de nuevos votantes desde 2008 (no más de medio millón). Además, en el proceso electoral de noviembre de 2011, el líder del PP no conseguía mucha mejor valoración que el líder socialista. Ninguno de los dos líderes, aunque uno de ellos ganara claramente las elecciones, tenía la confianza mayoritaria de la ciudadanía española. El PSOE perdió más de cuatro millones de votantes con respecto a los comicios de 2008. De este modo, el PP pudo ganar las elecciones como resultado del enorme desgaste experimentado por Rodríguez Zapatero y del vaciado ideológico que el líder leonés hizo en el PSOE para adoptar las nuevas medidas económicas de austeridad (Álvarez, 2011). Dicho vaciado ideológico provocó que muchos electores socialistas se abstuvieran o votaran a otras opciones políticas. 
Además, un examen pormenorizado de los resultados de las elecciones generales de 2011 lleva a destacar que la opción electoral mayoritaria se decantó por no ir a votar: unos 11.113.099 españoles se abstuvieron, lo que representa un 31,1 \% de los 35.779.491 votantes inscritos en el censo electoral en noviembre de 2011. Y en relación al total de votantes soberanos, sólo un $30 \%$ de los mismos (10.866.556 electores) apoyó expresamente la candidatura de Mariano Rajoy a la presidencia del gobierno. Igualmente, las de noviembre de 2011 son las primeras elecciones generales españolas en que se produjo una alternancia en el poder con una participación que se quedó en el 68,9\% de los votantes soberanos, dato de participación que coincide con el de las elecciones generales del año 2000 en las que José María Aznar obtuvo la mayoría absoluta. Por tanto, las elecciones del pasado 20 de noviembre de 2011 fueron de muy baja movilización y participación electoral en el contexto de las elecciones generales en España, en las que la participación media está en torno al $74 \%$ (Barbeito, 2012).

Por consiguiente, los referidos resultados electorales muestran una baja participación, al tiempo que cuestionaron claramente el liderazgo de Pérez Rubalcaba, precisamente el líder político más afectado por la alta abstención electoral. Efectivamente, los negativos resultados electorales parecían apartar al experimentado líder cántabro de cualquier tentación de dirigir el PSOE. Los políticos socialistas habían perdido la confianza y la credibilidad de una gran parte de sus propios votantes, a pesar de haber recambiado el liderazgo político en un complicado proceso (Delgado y Jiménez, 2012). Nunca antes en democracia, el PSOE había obtenido tan escasa representación en el Parlamento: sólo 110 diputados, lo que supuso una pérdida de 59 diputados en dicha institución respecto a las elecciones de 2008.

Pero estos hechos no eran nuevos en la Unión Europea, pues en tales circunstancias de grave crisis "quien gobierna, pierde" (Álvarez, 2011). Así, muchos gobernantes europeos (José Sócrates en Portugal, Giorgos Papandreu en Grecia, Nicolás Sarkozy en Francia, Silvio Berlusconi en Italia, etc.) habían soportado o iban a soportar una derrota electoral o una dimisión forzada del gobierno en pleno, como consecuencia de los negativos efectos de la crisis económica en sus respectivos países. Efectos que comportaron, en noviembre de 2011, la salida forzada o dimisión sobrevenida de Berlusconi en Italia y de Papandreu en Grecia, siendo ambos presidentes reemplazados por tecnócratas que no tenían la legitimidad democrática de haber sido elegidos en unas elecciones, pero sí disponían de la confianza de las élites políticas y económicas europeas. Dando cuenta de este convulso escenario, Ivan Krastov decía lo siguiente: "Las elecciones están perdiendo su significado de opción entre alternativas y se transforman en procesos a las elites. Así, la democracia ya no es cuestión de confianza, sino más bien de gestión de la desconfianza" (Krastov, citado en Estefanía, 2010:32). Es más, parece extenderse una cultura de la desconfianza frente al poder y una mayor preocupación por las prácticas de quienes gobiernan (ver Inglehart, et al., 2004), así como una ruptura del contrato moral entre representantes políticos y ciudadanos (Villoria, 2005).

Ante esta situación es preciso conocer los efectos que ha tenido y aún tiene la crisis económica y la gestión de la misma sobre los liderazgos políticos. Para ello ha de analizarse detenidamente la evolución del apoyo y/o grado de confianza que los ciudadanos depositan en sus líderes e instituciones políticas, así como reflexionar sobre los desafíos de los liderazgos democráticos en contextos sociopolíticos de creciente desconfianza política-institucional. 


\section{CONFIANZA POLÍTICA Y LIDERAZGOS DEMOCRÁTICOS: ¿UNA RELACIÓN NECESARIA?}

La creciente desconfianza en la política y las instituciones lleva a plantearse las siguientes preguntas: ¿qué grado de confianza política puede permitir a los líderes democráticos (elegidos por los ciudadanos) gobernar con cierta legitimidad popular? $\mathrm{O}$ en otras palabras: ¿con qué grado de desconfianza popular es posible gobernar democráticamente una sociedad?

Desde la teoría política y la ciencia política modernas las respuestas a tales preguntas, en principio, son claras. Así, existe un acuerdo generalizado en torno a que la confianza política es saludable para la democracia. Algunos estudiosos argumentan que altos niveles de confianza en los líderes políticos, los partidos políticos y las instituciones políticas son sinónimos de una buena democracia o de calidad democrática (Herreros, 2004; Robles Egea, 2012). Otros expertos afirman que la confianza política es un valioso activo para el funcionamiento y desempeño de las instituciones políticas en una sociedad democrática (Newton y Norris, 2000). Se supone que la confianza política afecta al deseo de los ciudadanos en general de pagar sus impuestos, al deseo de los más talentosos de esos ciudadanos de entrar en la administración pública, al cumplimiento voluntario de las leyes, $\mathrm{y}$, más en general, al cumplimiento voluntario de las políticas gubernamentales (Herreros, 2004). Por otra parte, la creciente personalización de la política lleva a que el grado de confianza institucional o política dependa de las evaluaciones concretas que la ciudadanía hace de los líderes políticos que representan las principales instituciones del Estado (Rico, 2009). De ahí lo conveniente de mostrar evidencias tanto de la confianza en los líderes políticos como en las instituciones.

La confianza política se muestra de forma dual: por un lado, puede ser institucional y macro-política, y, por otro, individual y micro-política. La primera aparece cuando los ciudadanos valoran las instituciones, los resultados de la gestión política, o a los líderes políticos, especialmente, en función de si cumplen sus expectativas $y$, por ende, considerándolos eficientes, transparentes y honestos (Llera, 2012). Se trata, pues, de un juicio político de la ciudadanía sobre la responsabilidad de las instituciones y sus gestores políticos, sostenido sobre unos principios y valores -o intuiciones democráticas- que se entienden como defendibles en una sociedad decente (equidad, imparcialidad, inclusión, justicia, etc.) y que los líderes públicos democráticos han de respetar (Villoria, 2005). De este modo, la confianza en las instituciones es un indicador fundamental de los sentimientos de la ciudadanía democrática sobre su sistema político (Newton y Norris, 2000:53). Por otra parte, la vertiente individual de la confianza política se refiere a las percepciones de las autoridades y líderes políticos en el ejercicio de sus cargos públicos. Este trabajo se centrará en el análisis de datos referidos a la confianza de los ciudadanos españoles (institucional) en los liderazgos políticos e instituciones representativas.

En lo que respecta a la literatura sobre liderazgo político, se ha reconocido tres aspectos relevantes del mismo: primero, "lo que cuenta realmente no es lo que el líder es sino aquello que los seguidores creen que es" (Martínez y Morales, 1998: s/p), por lo que las imágenes que los seguidores elaboran de los líderes son cruciales en las valoraciones de los primeros sobre los segundos. En segundo lugar, existe una estrecha relación entre liderazgo político y confianza, pues sobre todo los ciudadanos quieren gobernantes en los que poder confiar (Kouzes y Postner, 1993). Por tanto, "el liderazgo democrático ha de tener una fuerte legitimación basada en la confianza, la responsabilidad y el intercambio 
con los ciudadanos" (Robles Egea, 2012:114). Así, la principal premisa del liderazgo político democrático es que si no se cree en los líderes, tampoco se confiará en sus mensajes (Kouzes y Postner, 1993). En tercer lugar, en las democracias la confianza en los líderes políticos juega una función esencial (Natera, 2001), ya que "el vínculo entre representantes y representados se construye, fundamentalmente, sobre la confianza personal que inspiran los candidatos" (Rico, 2009:338-339). En suma, si los ciudadanos desconfían de sus líderes democráticamente elegidos, éstos últimos no podrán convencer con sus discursos a los primeros, lo que, a su vez, puede originar una progresiva deslegitimación de la política y ruptura del contrato moral entre gobernantes y gobernados en una democracia.

La desconfianza se puede originar por muy distintos motivos, tales como: la falta de resultados, la frustración y/o cambio de expectativas sociales, el mal funcionamiento regulador de los conflictos de intereses, la falta de transparencia en la gestión de actores e instituciones, su ineficiencia e ineficacia o por la corrupción de la clase política. En definitiva, la constatación de un largo tiempo de desconfianza social y política puede tener consecuencias letales para las instituciones y los gobiernos democráticos (Llera, 2011), dando lugar a lo que algunos autores han denominado como la desaparición de la confianza pública y la crisis de legitimidad política (Castells, 2009:376-389). En el siguiente apartado se muestra que los principales líderes políticos españoles entre 2008 y 2012, así como las principales instituciones democráticas, han experimentado una creciente desconfianza de la ciudadanía española. Desconfianza que puede acentuarse por la gravedad y efectos perniciosos que en España tiene la crisis económica.

\section{Gráfico 1: Indicador del grado de confianza política}

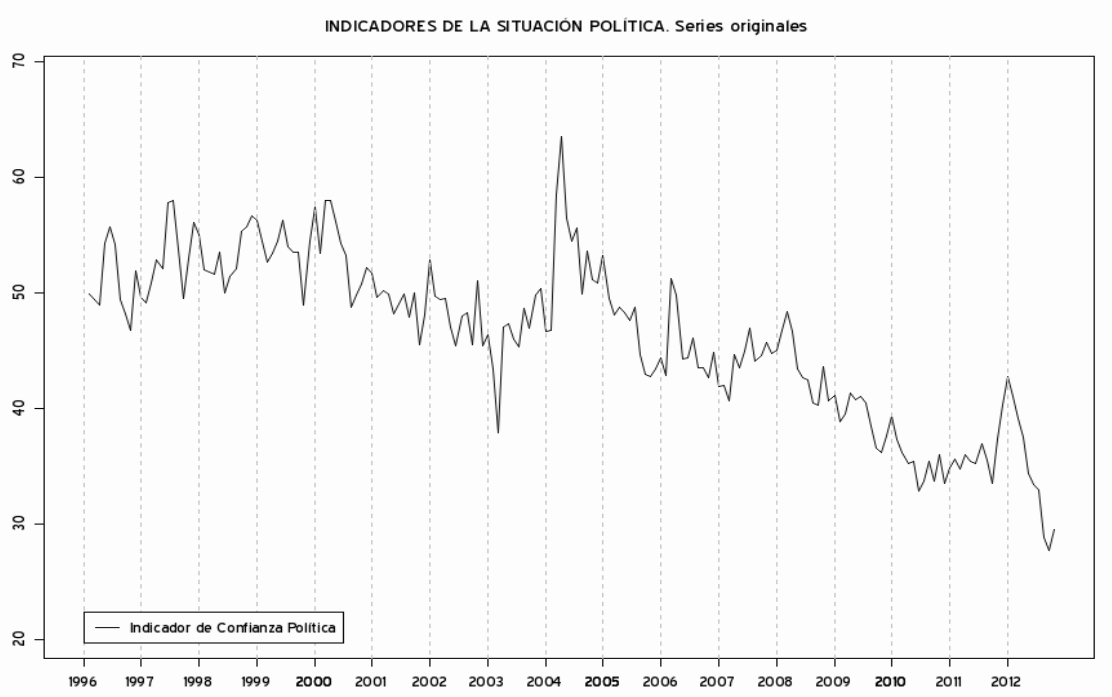

Fuente: CIS, serie actualizada en noviembre de 2012. http://www.cis.es/cis/opencms/ES/11_baro metros/Indicadores_PI/documentos/serPol1.html (Consulta: 6/12/2012). 
Los estudios de opinión pública que registran los niveles de confianza gubernamental e institucional confirman un declive generalizado y consistente de la confianza institucional desde, por lo menos, el año 2004 (Llera, 2012).

El gráfico 1, que considera la serie temporal del indicador sintético elaborado por el CIS (actualizado hasta noviembre de 2012), muestra el declive de la confianza política en España. Tal declive de la confianza es continuado desde el nivel registrado en 1996 (en torno al $50 \%$ ) al nivel actual (inferior al $30 \%$ ). Nunca antes en las series temporales elaboradas por el CIS la confianza política en España había estado por debajo del $30 \%$. La recuperación producida por el cambio de gobierno en diciembre de 2011 fue realmente efímera. Esta recuperación fue mucho menor que la apreciada después del triunfo socialista en las elecciones generales de 2004, cuando se llegó a superar el $60 \%$. Además, tras la recuperación de los primeros días del gobierno de Mariano Rajoy, se produjo pocos meses después un desplome del referido indicador. Se confirma así una auténtica crisis de confianza política intensificada, a partir de 2008, a raíz de la crisis económica. La crisis de confianza puede agravarse aún más con la aplicación de las medidas económicas del gobierno de Rajoy, desde julio de 2012, como las subidas de impuestos, la supresión de la paga extraordinaria de diciembre a los empleados públicos y la no revalorización de las pensiones.

\section{DESCONFIANZA EN LOS LIDERAZGOS E INSTITUCIONES DEMOCRÁTICAS}

La primera fase de la trayectoria democrática en España estuvo caracterizada por la política de acuerdos en temas básicos, liderazgos fuertes e innovadores tanto en el gobierno como en la oposición (Linz, 2001; Llera, 2011). De hecho, Adolfo Suárez y Felipe González vivieron un contexto mucho más favorable para la aparición de liderazgos fuertes. No obstante, ello no evitó el deterioro en la valoración y confianza de dichos Presidentes del Gobierno, pues ambos finalizaron sus mandatos con un gran declive de su credibilidad pública, si bien González pudo ganar sus últimas elecciones (1993) cuando el país atravesaba una grave crisis económica.

Pero en el caso de José Luis Rodríguez Zapatero su enorme pérdida de credibilidad en los dos últimos años de su mandato no se compensó, por primera vez, con una percepción positiva del líder del principal partido de oposición (Mariano Rajoy), tal y como se muestra en los dos gráficos siguientes (gráfico 2 y gráfico 3). No deja de sorprender que Mariano Rajoy ganase unas elecciones generales por mayoría absoluta, el 20 de noviembre de 2011, con un porcentaje de desconfianza ciudadana por encima del $70 \%$ y con apenas una confianza del 26\%. También sorprende que Alfredo Pérez Rubalcaba aún no haya recuperado la confianza de los ciudadanos e incluso los que se dicen votantes del PSOE manifiestan una desconfianza del 57\% hacia dicho líder socialista (CIS, 2012: estudio 2.951, pregunta 15). Estos datos deberían hacer reflexionar, no sólo a los investigadores interesados en este asunto, sino también a la clase política y a los ciudadanos acerca de la gravedad de la situación política en la que se encuentra España. 
Gráfico 2: Confianza en los líderes del PSOE: Rodríguez Zapatero y Rubalcaba

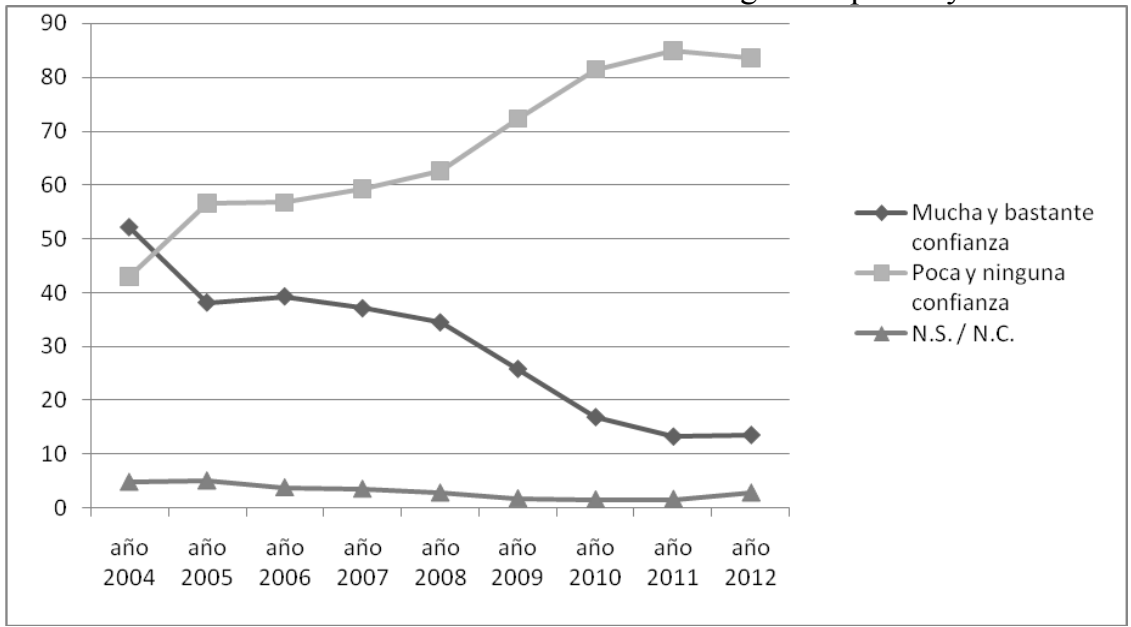

Fuente: Elaboración propia con Series temporales del Centro de Investigaciones Sociológicas (CIS), mes de octubre de cada año. (2004-2011). Los datos de 2012 se basan en la pregunta 15 del Barómetro de julio de 2012 (CIS, 2012: Estudio 2.951). Pregunta de las series temporales: "El Presidente del Gobierno, José Luis Rodríguez Zapatero, ¿Le inspira, personalmente, mucha confianza, bastante confianza, poca o ninguna confianza?" http://datosbd.cis.es/ciswebconsultas/ serieFichaViewPreguntaList.htm?idPregunta $=244254 \&$ idSerie $=$ B $101030200 \&$ from $=$ preguntaSearch (Consulta: 15 de julio de 2012).

Gráfico 3: Confianza en el líder del PP: Mariano Rajoy

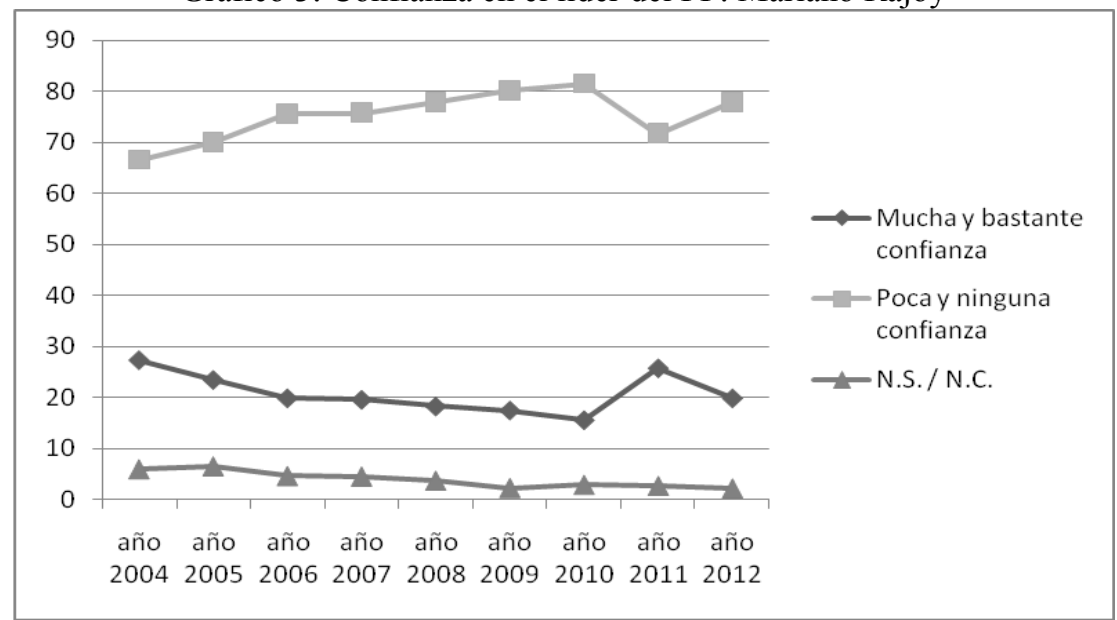

Fuente: Elaboración propia con Series Temporales del Centro de Investigaciones Sociológicas (CIS), mes de octubre de cada año (2004-2011). Los datos de 2012 se basan en la pregunta 14 del Barómetro de julio de 2012 (CIS, 2012: Estudio 2.951). Pregunta de las series temporales: "¿Y el Presidente del PP, Mariano Rajoy, le inspira personalmente mucha confianza, bastante confianza, poca o ninguna confianza?" http://datosbd.cis.es/ciswebconsultas/serieFichaViewPreguntaList.htm? idPregunta $=244256 \&$ idSerie $=A 501030090 \&$ from $=$ preguntaSearch $($ Consulta: 15 de julio de 2012). 
De acuerdo con el barómetro del Centro de Investigaciones Sociológicas de julio de 2011, las valoraciones del Presidente del Gobierno José Luis Rodríguez Zapatero y del líder del PP Mariano Rajoy obtenían un claro suspenso: 3,47 y 3,58 respectivamente, en una escala de 0 a 10 puntos, sólo superando escasamente el aprobado en sus respectivos electorados. Los ciudadanos percibían al Partido Popular como más capaz que el PSOE para gestionar el empleo y la economía, en tanto al PSOE se le veía más capacitado que al PP para gestionar la educación y las políticas sociales. No obstante, a pesar de que los encuestados tenían más confianza en el PP para gestionar los principales problemas económicos, los ciudadanos creían que Pérez Rubalcaba (39,9 \%) sería mejor Presidente del Gobierno que Rajoy (31,9 \%) y, además, se percibía al primer líder como más eficaz, más dialogante y con más visión de futuro que el segundo. El político mejor valorado en julio de 2011, aunque no conseguía aprobar, era el líder nacionalista Josep A. Duran i Lleida $(4,02)$. Un poco por detrás quedaba Rosa Díez $(3,95)$ y el líder de Izquierda Unida, Cayo Lara, sólo obtenía un 3,03. La clase política se veía como el tercer problema para los españoles $(23,9 \%)$, después del paro $(81,1 \%)$ y los problemas de índole económica $(49,5$ \%) (CIS, 2011: estudio 2.909).

Un año después (julio de 2012), la valoración de Mariano Rajoy $(3,33)$ era aún más baja que la que obtenida en julio de 2011 por Rodríguez Zapatero, en tanto que el liderazgo de Pérez Rubalcaba tampoco acababa de remontar con una valoración de 3,80 sobre 10. El líder político mejor valorado, en julio de 2012, era Rosa Díez $(4,36)$. A ella le seguían: Uxue Barcos $(4,07)$, Cayo Lara $(3,77)$ y Duran i Lleida $(3,77)$. Así, los dirigentes políticos de partidos minoritarios de ámbito nacional (UPyD e IU) obtuvieron mejores valoraciones que en 2011. Sin embargo, los ciudadanos desconfiaban de los principales líderes políticos, puesto que Pérez Rubalcaba únicamente obtenía un grado de confianza del 14\% (sólo el $39,5 \%$ entre los votantes socialistas) y Mariano Rajoy sólo lograba la confianza del 20\% (aunque con un 57\% entre los votantes del PP), obteniendo ambos líderes bajas o muy bajas valoraciones. Además, la clase política se consolidó como el tercer problema para los españoles $(25,4 \%)$, apareciendo la corrupción y el fraude como el cuarto problema para un 12,2\% de los encuestados (CIS, 2012: estudio 2.951).

Sin duda, los anteriores datos confirman la gravedad de la crisis política que se vive en España. Crisis que no sólo se traduce en la desconfianza en los liderazgos políticos, sino que se expande hacia la desconfianza en las principales instituciones democráticas de nuestro país. Efectivamente, el grado de confianza de la ciudadanía española en los Partidos políticos, en el Parlamento, el Gobierno central y el Poder judicial, en tanto principales instituciones de la democracia, ha experimentado un fuerte deterioro en los últimos años (ver gráfico 4, gráfico 5, gráfico 6, gráfico 7). Los siguientes gráfícos muestran que la crisis no es sólo económica, sino que también es institucional y política, lo que lleva a los ciudadanos a reclamar una mayor calidad de las instituciones que les gobiernan y que quienes gobiernan lo hagan considerando los intereses generales y no en favor de ciertos grupos privilegiados. No se puede olvidar que "las crisis multiplican la inseguridad de los ciudadanos y en este contexto cobran más significación las instituciones. La historia muestra que cada vez que se produce una crisis tan extrema, los ciudadanos redescubren la necesidad de instituciones eficaces, de estar bien gobernados, la importancia de lo colectivo [...]" (Estefanía, et al., 2010:29). 
Gráfico 4: Confianza de los ciudadanos en los Partidos políticos

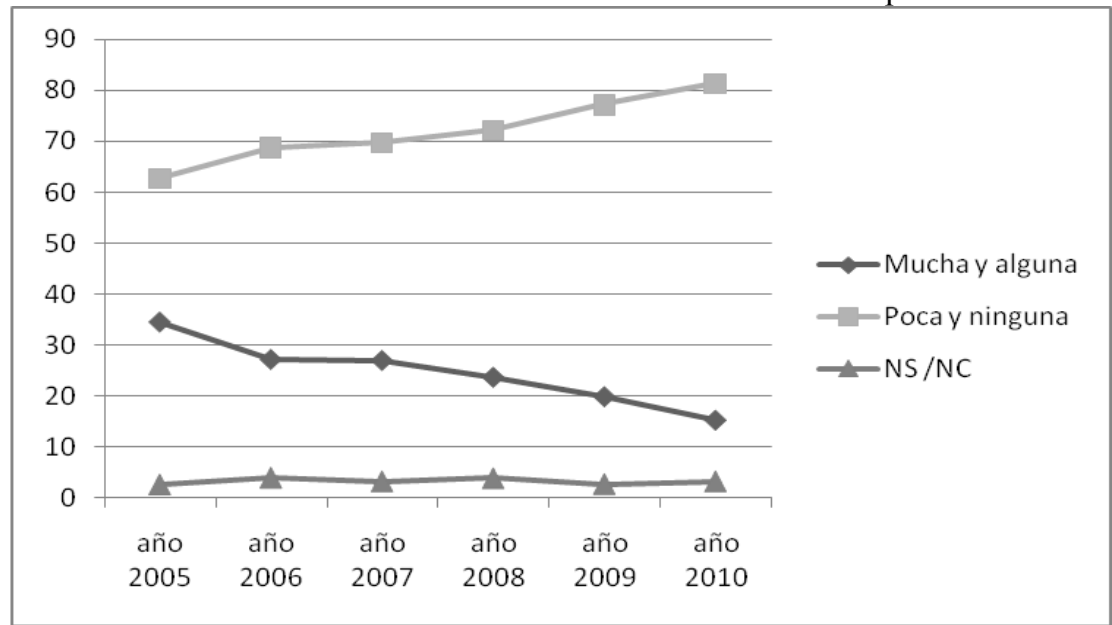

Fuente: Elaboración propia y Series Temporales del Centro de Investigaciones Sociológicas (CIS). Pregunta de las series temporales: “¿Me podría decir Ud. cuánta confianza tiene Ud. en cada uno de los siguientes grupos o instituciones: mucha, alguna, poca o ninguna?: Los partidos políticos". http://datosbd.cis.es/ciswebconsultas/serieFichaView.htm?idSerie=A102060150\&from=serieList (Consulta: 15 de julio de 2012).

Gráfico 5: Confianza de los ciudadanos en el Parlamento

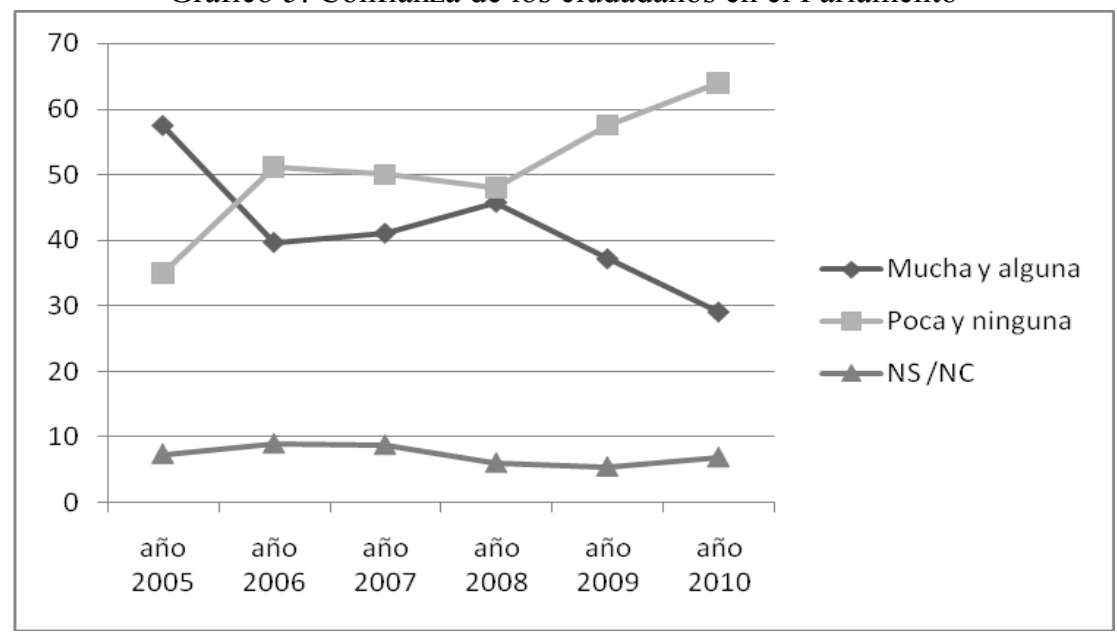

Fuente: Elaboración propia y Series Temporales del Centro de Investigaciones Sociológicas (CIS). Pregunta de las series temporales: “¿Me podría decir Ud. cuánta confianza tiene Ud. en cada uno de los siguientes grupos o instituciones: mucha, alguna, poca o ninguna?: El Congreso de los Diputados". (Consulta: 15 de julio de 2012). http://datosbd.cis.es/ciswebconsultas/serieFichaView. $\mathrm{htm}$ ?idSerie $=\mathrm{A} 102060040 \&$ from $=$ serieList 
Gráfico 6: Confianza de los ciudadanos en el Gobierno central

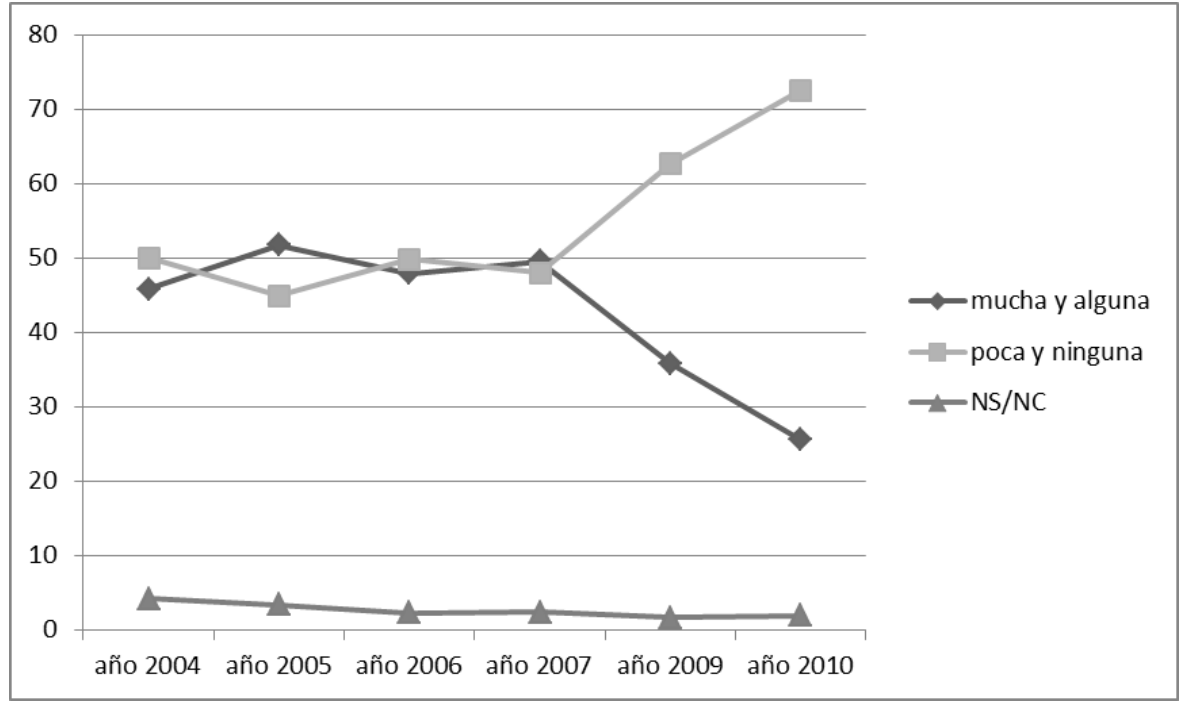

Fuente: Elaboración propia y Series Temporales del Centro de Investigaciones Sociológicas (CIS). Pregunta de las series temporales: "¿Me podría decir Ud. cuánta confianza tiene Ud. en cada uno de los siguientes grupos o instituciones: mucha, alguna, poca o ninguna?: El Gobierno" (Consulta: 6 de diciembre de 2012). http://datosbd.cis.es/ciswebconsultas/serieFichaView.htm?idSerie=A102060 030\&from $=$ serieList

Gráfico 7: Confianza de los ciudadanos en el Poder judicial

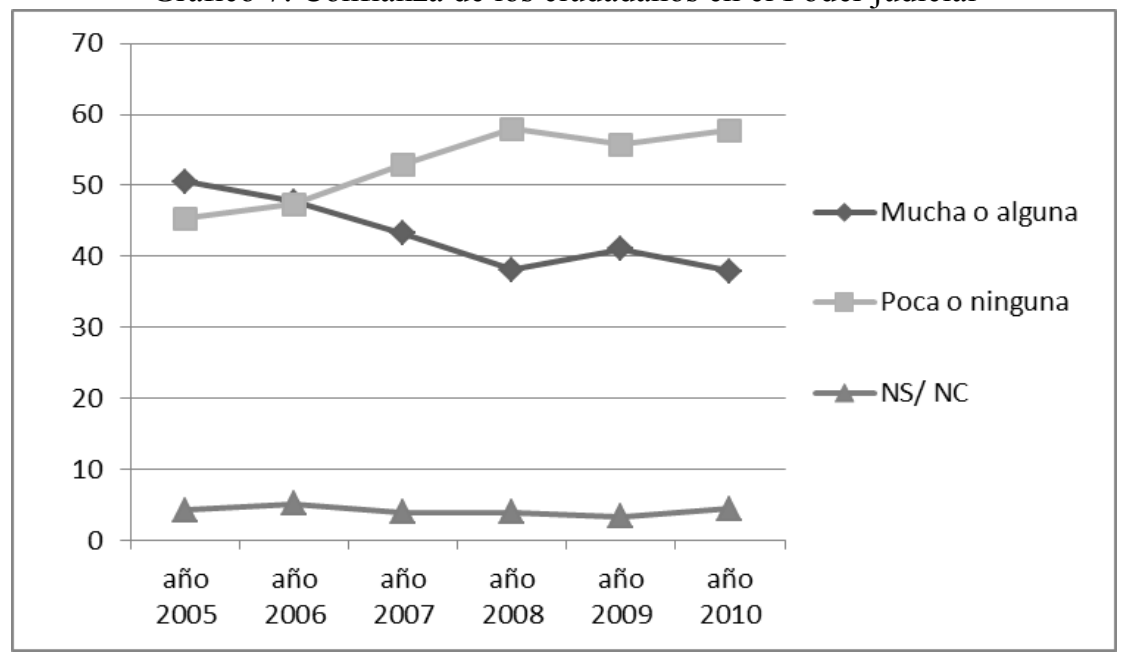

Fuente: Elaboración propia y Series Temporales del Centro de Investigaciones Sociológicas (CIS). Pregunta de las series temporales: "¿Me podría decir Ud. cuánta confianza tiene Ud. en cada uno de los siguientes grupos o instituciones: mucha, alguna, poca o ninguna?: El Poder Judicial" (Consulta: 6 de diciembre de 2012). http://datosbd.cis.es/ciswebconsultas/serieFichaView.htm?id Serie $=$ A102060050\& from $=$ serieList 


\section{A MODO DE REFLEXIÓN}

Desde hace tres décadas, aproximadamente, se muestra una creciente desconfianza en la práctica totalidad de las democracias más consolidadas del mundo (Norris, 1999; Newton y Norris, 2000; Pharr y Putnam, 2000; Dogan, 2005; Toharia, 2012), en las que la mayoría de ciudadanos "no confía en sus gobiernos ni en sus parlamentos y un grupo aún mayor de ciudadanos desprecia a los políticos y a los partidos y cree que su gobierno no representa la voluntad popular" (Castells, 2009:376). En el caso español, dicha desconfianza proviene del desarrollo de la "política de adversarios" y de la consiguiente dinámica conflictiva y de polarización entre los principales actores políticos desde comienzos de los años noventa (Llera, 2011). Este deterioro de la confianza política en las instituciones democráticas y los líderes políticos conlleva una crisis de legitimidad que se agudiza como consecuencia de los efectos amplificadores de la crisis económica.

No obstante, el declive de la confianza política en España se puede explicar por diversos factores. Primero, el creciente grado de percepción ciudadana de corrupción en las organizaciones políticas y económicas con su consiguiente descrédito público (Villoria, 2005). Se ha de recordar que en el último lustro se han desvelado graves casos de corrupción que afectan a los principales partidos políticos de ámbito estatal (Caso Gürtel, Caso de los EREs en Andalucía e innumerables casos de corrupción local), así como graves desviaciones que afectan al sistema financiero nacional (participaciones preferentes emitidas por bancos y cajas de ahorro, conflictos de interés entre la clase política y la élite económica, etc.). Segundo, en el presente contexto de crisis económica europea, existe una falta de visión política y liderazgo europeo, lo que imposibilita hacer un diagnóstico común y creíble de los problemas que afectan a la Unión Europea (UE). Con lo cual, los líderes políticos españoles son incapaces de idear una salida creíble de la crisis financieraeconómica y tampoco redistribuyen equitativamente los costos sociales de dicha crisis. Tercero, la clase política española es percibida por los ciudadanos como excesivamente polarizada y sin voluntad de consenso en los temas importantes, hasta el punto de que dicha clase es vista como el tercer problema para los españoles, después del paro y los problemas económicos. No es baladí, que casi un $90 \%$ de los españoles crean que los partidos políticos han abandonado el espíritu de consenso de la Transición y únicamente piensan en sus intereses particulares (Toharia, 2012). Por último, la creciente globalización financiera dificulta la gestión política de la crisis económica europea y los líderes nacionales se muestran incapaces de acordar decisiones comunes vinculantes que respondan a la gravedad de la situación.

De hecho, quienes dirigen las organizaciones financieras y las corporaciones multinacionales, muchas veces en connivencia con la clase política, ostentan más poder de decisión que los gobernantes nacionales a la hora de decidir sobre las posibles soluciones a la crisis económica. Y lo más inquietante "es la insuficiencia de transparencia que ha desvelado el funcionamiento del sistema financiero más avanzado del mundo" (Ontiveros, 2009: 10). Así, los líderes políticos europeos se tornan impotentes para regular la crisis en favor de la ciudadanía, y los principales órganos políticos y económicos de la UE, Comisión Europea, Banco Central Europeo y Parlamento Europeo, que deberían desempeñar un papel importante en la gestión de los problemas políticos y económicos que aquejan a toda Europa, no tienen el poder decisorio ni la legitimidad necesaria para abordar tales problemas. Al final son los estados más poderosos -Alemania y Francia- los que imponen sus propios criterios para una supuesta salida "común" de la crisis. 
De esta forma, se muestra que el proyecto de la UE está pensado y dirigido por las élites políticas y económicas sin considerar los intereses reales de los ciudadanos, pues las primeras parecen gobernar de espalda a los segundos. No en vano, el hecho de que en Grecia e Italia se impusieran gobiernos dirigidos por tecnócratas estuvo precedido por "casi dos años de dudas y divisiones, falta de coraje y de visión política para adoptar una solución europea [que] están cebando la desafección ciudadana, tanto hacia las democracias nacionales como hacia el propio proyecto europeo" (Torreblanca, 2011). Todo ello se acompaña de un preocupante avance del populismo xenófobo en Europa. Así, en países como Francia, Finlandia, Grecia y Holanda los partidos de extrema derecha, que basaron sus campañas electorales en el rechazo a la inmigración y a la UE (Gómez, 2011), obtuvieron unos resultados electorales decisivos para influir en la formación de gobiernos. Estas circunstancias llevan a la aparición de una suerte de totalitarismo invertido, que se origina y desarrolla en una ciudadanía cada vez menos comprometida con sus deberes cívicos, y donde "los ciudadanos han elegido renunciar a la política participativa" (Wolin, 2008:126).

Sin duda, el presente escenario de crisis e incertidumbres lleva a que los ciudadanos prefieran la estabilidad y seguridad económica, en detrimento del compromiso político. Ello, unido a la impotencia de las clases políticas nacionales para deliberar y gobernar de forma autónoma, lleva a que en países como España la clase política sea uno de los principales problemas para los ciudadanos, en tanto que líderes y partidos políticos (y bancos) suscitan la menor confianza entre la ciudadanía. Estos hechos constatan una profunda crisis de confianza en las instituciones políticas españolas y en sus dirigentes. Así lo demostró, por ejemplo, el movimiento social de los indignados que denunciaba los problemas del sistema político y económico español. Este malestar democrático se agrava al tratar de imponer entre la ciudadanía la visión interesada de los poderes políticos, económicos, financieros y mediáticos dominantes, que producen y reproducen una democracia sin ciudadanos, en la cual "sólo quienes tienen poder económico, tienen a su vez capacidad real para expresarse y dominar el universo mediático e incluso el político" (Camps, 2010:155). En tal sentido, no es resultado del azar que se haya producido una globalización de las protestas (Stiglitz, 2011), puesto que los ciudadanos disponen de mayor acceso a la información, incluso pudiendo producirla con las nuevas tecnologías, al tiempo que conviven con todas las incertidumbres propias de la globalización (Entrena, 2009). Ante este cambiante contexto queda la esperanza de que la ciudadanía reclame unos liderazgos e instituciones democráticas renovadas (un reclamo que aparece en diversos sondeos de opinión y auditorías democráticas) que estén predispuestas a actuar con más vocación, responsabilidad, honestidad y transparencia pública.

\section{BIBLIOGRAFÍA}

ÁlVAREZ, J.L. (2011), “Después de Zapatero, el PSOE”, en El País, 2 de abril.

BARBEITO, R.L. (2012), "Participación y abstención en las elecciones generales de 2011", en P. Madrigal y E. Carrillo (eds.): Nuevos tiempos, nuevos retos, nuevas sociologías, Asociación Castellano Manchega de Sociología, Toledo, pp. 789-800.

BOIN, A. et al. (2007), La política de la gestión de crisis. El liderazgo público bajo presión, Madrid, Instituto Nacional de Administración Pública. 
CAMPS, V. (2010), "El ejercicio cívico de la libertad de expresión”, en V. Camps (ed.), Democracia sin ciudadanos, Madrid, Trotta, pp. 151-174.

CASTELLS, M. (2009), Comunicación y Poder, Madrid, Alianza.

CIS (2011), Barómetro de Opinión, julio de 2011, Estudio 2.909, Madrid, Centro de Investigaciones Sociológicas.

CIS (2012), Barómetro de Opinión, julio de 2012, Estudio 2.951, Madrid, Centro de Investigaciones Sociológicas.

DELGADO, S. y JIMÉNEZ, J.F. (2012), "En torno a la renovación del liderazgo político en el PSOE. Un análisis en perspectiva comparada con los partidos homólogos en América Latina", en Actas del I Congreso Internacional en Comunicación Política y Estrategias de Campaña, Madrid, 67 de julio de 2012.

DOGAN, M. (ed.) (2005), Political Mistrust and the Discrediting of Politicians, Leiden, Brill Academic Publishers.

ENTRENA, F. (2009), "Understanding Social Structure in the Context of Global Uncertainties", en Critical Sociology 35, $\mathrm{n}^{\circ} 4$, pp. 521-540.

ESTEFANÍA, J. (dir.) et al. (2010), Informe sobre la democracia en España / 2010. La erosión de la confianza y el bienestar. Contra la desafección ciudadana, Madrid, Fundación Alternativas.

ESTEFANÍA, J. (dir.) et al. (2012), Informe sobre la democracia en España / 2012, Madrid, Fundación Alternativas.

GAREA, F. (2010), "El debate de la Nación más crítico". El País, 15 de julio. http://elpais.com/ elpais/2010/07/15/actualidad/1279181817_850215.html, visitado: 18/06/2012.

GÓMEZ, J. (2011), "El populismo amenaza la zona euro", en El País, 19 de abril.

GONZÁLEZ, F. (2010), Mi idea de Europa, Barcelona, RBA Libros.

HERREROS, F. (2004), "La confianza política en la tradición republicana desde Cicerón hasta Madison", en Revista de Estudios Políticos, 125, pp. 325-347.

INGLEHART, R. et al. (2004), Human Beliefs and Values, México, Siglo XXI.

JIMÉNEZ, J.F. y COLLADO, F. (2011), "Contexto político y semblanza biográfica de José Luis Rodríguez Zapatero", Revista Espacios Públicos, 31, pp. 136-157.

KOUZES, J.M. y POSTNER, B.Z. (1993), "The credibility factor: What people expect of leaders", en W.E. Rosenbach y R.L. Taylor (eds.), Contemporary Issues in Leadership, San Francisco, Westview Press.

LINZ, J.J. (2001), "El liderazgo innovador en la transición a la democracia y en una nueva democracia" en M. Alcántara y A. Martínez, (eds.), Política y Gobierno en España, Valencia, Tirant lo Blanch, pp. 57-97.

LLERA, F.J. (2011), "La crisis política”, en J.J. TOHARIA (ed.), Pulso de España 2010: un informe sociológico, Madrid, Biblioteca Nueva, pp. 69-83.

LLERA, F.J. (2012), “Crisis y desafección política en la encrucijada andaluza”, en Foro de Expertos (Acta XV), Centro de Estudios Andaluces, Sevilla.

MARTÍNEZ, A. y MORALES, J.F. (1998), "El debate en torno al locus del liderazgo político", en Actas del I Congreso Iberoamericano, Colegio Oficial de Psicólogos, Madrid.

NATERA, A. (2001), El liderazgo político en la sociedad democrática, Madrid, Centro de Estudios Políticos y Constitucionales.

NEWTON, K. y NORRIS, P. (2000), "Confidence in Public Institutions: Faith, Culture or Performance?" en S.J. Pharr y R.D. Putnam (eds.) Disaffected Democracies: What's Troubling the Trilateral Countries?, Princeton, Princeton University Press.

NORRIS, P. (1999), Critical Citizens: Global Support for Democratic Government, Oxford, Oxford University Press.

ONTIVEROS, E. (2009), "En el umbral de otra época", Revista de Economía, no 119, pp. 17-20.

PHARR, S.J. y PUTNAM, R.D. (eds.) (2000), Disaffected Democracies, Princeton, Princeton University Press.

RICO, G. (2009), Líderes políticos, opinión pública y comportamiento electoral en España, Madrid, Centro de Investigaciones Sociológicas. 
ROBLes EGEA, A. (2012), "Líderes Para Una Democracia De Calidad”, en A. Robles Egea y R. Vargas-Machuca (eds.), La buena democracia. Claves de su calidad, Granada, Editorial Universidad de Granada.

SASSEN, S. (2012), "Se ha roto el ciclo, porque el salario del trabajador ya no permite mantener el consumo", en El País Semanal, 29 de enero, pp. 24-27.

STIGLITZ, J.E. (2011), "La globalización de la protesta", en El País, 6 de noviembre.

TOHARIA, J.J. (2012), "Los españoles y las instituciones / y 5. Altruistas y protectores", en El País, 2 de septiembre.

TORREBLANCA, J.I. (2011), "La democracia puesta a prueba", en El País, 12 de noviembre.

VILLORIA, M. (2005), "Corrupción y liderazgo público", VII Congreso Español de Ciencia Política y de la Administración: Democracia y Buen gobierno, http://www.aecpa.es/uploads/files/congresos /congreso_07/area06/GT24/VILLORIA-MENDIETA-Manuel(URJC).pdf, visitado: 10/12/2012.

WOLIN, S.S. (2008), Democracia S.A. La democracia dirigida y el fantasma del totalitarismo invertido, Madrid, Katz Editores.

\section{Breve currículo}

\section{José Francisco Jiménez Díaz}

Doctor en Sociología por la Universidad de Granada. Profesor de Ciencia Política y de la Administración en la Universidad Pablo de Olavide (Sevilla). Sus temas principales de investigación son liderazgo político democrático, teorías políticas normativas y efectos locales de la globalización. Sobre estos temas ha publicado artículos en revistas de ciencias sociales, libros y capítulos de libro. Durante los últimos cinco años ha participado en varios proyectos de investigación $\mathrm{I}+\mathrm{D}$, financiados por el Ministerio de Educación y la Junta de Andalucía. Además, ha realizado estancias de investigación posdoctorales en la London School of Economics and Political Science (LSE) y en el Instituto Superior de Ciências Sociais e Políticas de la Universidad Técnica de Lisboa (ISCSP). 